\title{
Case Volume Does Not Correlate With Outcome After Cerebral Aneurysm Clipping: A Nationwide Study in Japan
}

\author{
Naoyuki HATTORI, Yoichi KATAYAMA, and Takumi ABE* \\ The Japan Neurosurgical Society
}

Department of Neurosurgery, Nihon University School of Medicine, Tokyo;

${ }^{*}$ Department of Neurosurgery, Showa University School of Medicine, Tokyo

\begin{abstract}
The present study analyzed the impact of case volume on outcome after cerebral aneurysm clipping at all 382 core neurosurgical training centers certified by the Japan Neurosurgical Society. A survey requested information on all clipping surgeries for cerebral aneurysms performed during 2003. Among these centers, $369(96.6 \%)$ responded to our request and data satisfactory for analysis were obtained for 11,974 patients. Clinical condition was graded on admission according to the classification of the World Federation of Neurosurgical Societies. Outcomes were evaluated at discharge using the modified Rankin scale. Case volume at centers was divided into three groups based on the number of clippings $(<30,30-50, \geq 50)$ performed in 2003 . Totals of $7,578(63.3 \%)$ and $4,396(36.7 \%)$ patients underwent clipping for ruptured and unruptured aneurysms, respectively. The mortality rate was $9.6 \%$ for patients with ruptured aneurysms, and $0.2 \%$ for patients with unruptured aneurysms. No significant correlation was detected between case volume and outcome for either ruptured (Spearman's correlation coefficient $=\mathbf{0 . 0 3 4}, \mathbf{p}=\mathbf{0 . 4 8 3}$ ) or unruptured aneurysms (Spearman's correlation coefficient $=\mathbf{0 . 0 2 9}, \mathbf{p}=\mathbf{0 . 5 6 2}$ ). Furthermore, no relationships between case volume and outcome were identified for ruptured aneurysms in each neurological grade or unruptured aneurysms (Kruskal-Wallis test).
\end{abstract}

Key words: cerebral aneurysm, case volume, outcome, clipping

\section{Introduction}

The Ministry of Health, Labor and Welfare of Japan has established center standards for 110 surgical procedures as a basis for the compensation system, in which centers not meeting such standards receive reduced payment. Center standards in the field of neurosurgery have been established for cerebral aneurysm clipping, which stipulate that full compensation is paid to centers with $\geq 50$ cases/year or centers with $\geq 30$ cases/year where board-certified neurosurgeons perform surgery, whereas compensation is reduced by $30 \%$ to centers not meeting these caseload requirements. The underlying assumption is that higher case volume results in greater experience and consequently higher surgical skill. However, this assumption requires validation by studies of the relationships between case volume and outcome..$^{2,4,16,20)}$ Several studies have investigat-

Received July 20, 2006; Accepted September 26, 2006 ed the relationships between case volume and outcome in cerebral aneurysm clipping in the United States (US). ${ }^{1,3,5,6,15,18,19)}$ However, the results of studies conducted in countries with different medical systems, medical standards, and specialist training systems cannot necessarily be used to establish center standards in Japan.

The present report describes a nationwide study conducted by the Japan Neurosurgical Society to investigate the relationships between case volume and outcome in cerebral aneurysm clipping procedures.

\section{Material and Methods}

Survey forms were mailed to 382 centers accredited as Class A specialist training facilities by the Japan Neurosurgical Society, to collect the details of cerebral aneurysm clipping procedures for both ruptured and unruptured cerebral aneurysms performed from January to December 2003. Clipping of multiple cerebral aneurysms associated with rup- 
Table 1 Clinical grading of patients with ruptured aneurysms (World Federation of Neurosurgical Societies scale)

\begin{tabular}{lcc}
\hline Grade & $\begin{array}{c}\text { Glasgow } \\
\text { Coma Scale }\end{array}$ & $\begin{array}{c}\text { Neurological deficit } \\
\text { (paralysis and/or aphasia) }\end{array}$ \\
\hline I & 15 & - \\
II & $13-14$ & - \\
III & $13-14$ & + \\
IV & $8-12$ & + or - \\
V & $3-7$ & + or - \\
\hline
\end{tabular}

Table 2 Outcome grading of patients with ruptured and unruptured aneurysms (modified Rankin scale)

\begin{tabular}{cl}
\hline Score & \\
\hline 0 & $\begin{array}{l}\text { No symptoms } \\
\text { Minor symptoms which do not interfere with } \\
\text { lifestyle }\end{array}$ \\
2 & $\begin{array}{l}\text { Minor handicap which leads to some restriction } \\
\text { in lifestyle but does not interfere with the } \\
\text { patients capacity to look after themselves } \\
\text { Moderate handicap which significantly restricts } \\
\text { lifestyle and prevents a totally independent } \\
\text { existence } \\
\text { Moderately severe handicap which clearly } \\
\text { prevents an independent existence though not } \\
\text { needing constant attention } \\
\text { Severe handicap requiring constant attention } \\
\text { night and day } \\
\text { Death }\end{array}$ \\
6
\end{tabular}

tured cerebral aneurysm during a single hospitalization was classified as ruptured cerebral aneurysm clipping, whereas clipping surgery performed after readmission was classified as unruptured cerebral aneurysm clipping. Survey forms also gathered information about other direct interventions, such as wrapping and trapping, but only data related to clipping were analyzed.

The clinical condition on admission of the patients with ruptured cerebral aneurysm was assessed according to the grading scale established by the World Federation of Neurosurgical Societies ${ }^{8)}$ (WFNS grades I-V, Table 1), and the outcomes at discharge of the patients with ruptured and unruptured aneurysm were assessed using a modified Rankin scale ${ }^{21)}$ (scores 0-6, Table 2). The total number of cerebral aneurysm clipping procedures, including both ruptured and unruptured cerebral aneurysms, during 2003 was taken as the case volume at each center.

The relationships between case volume and outcome at discharge, and between WFNS grade on
Table 3 Correlation between case volume, clinical grade, and outcome

\begin{tabular}{lcc}
\hline & $\begin{array}{c}\text { Spearman's rank } \\
\text { correlation } \\
\text { coefficient with } \\
\text { outcome grade* }\end{array}$ & p Value \\
\hline $\begin{array}{c}\text { Case volume** } \\
\text { ruptured aneurysms }\end{array}$ & 0.034 & 0.483 \\
$\quad \begin{array}{c}\text { unruptured aneurysms } \\
\text { Clinical grade*** } \\
\text { ruptured aneurysms }\end{array}$ & 0.029 & 0.562 \\
\hline
\end{tabular}

${ }^{*}$ Modified Rankin scale. ${ }^{* *}$ No. of clippings/year in treating hospital. ${ }^{* * *}$ World Federation of Neurosurgical Societies scale.

admission and outcome at discharge after clipping of ruptured cerebral aneurysms at each center were analyzed with Spearman's rank correlation coefficient. The relationships between case volume and outcome at discharge after clipping of unruptured cerebral aneurysms at each center was analyzed with Spearman's rank correlation coefficient.

The participating centers were classified into three groups by case volume $(<30,30-49$, and $\geq 50$ cases/year). The relationships between the case volume and outcome at discharge were assessed using the Kruskal-Wallis test. Values of $\mathrm{p}<0.05$ were considered statistically significant.

\section{Results}

Survey forms were returned by 369 of the 382 centers $(96.6 \%)$, and a total of 12,035 cerebral aneurysm clipping procedures were registered. However, descriptions with missing data such as WFNS grade on admission and outcome at discharge were excluded, so the final analysis included 11,974 cerebral aneurysm clipping procedures (99.5\%), 7,578 ruptured cerebral aneurysms $(63.3 \%)$ and 4,396 unruptured cerebral aneurysms (36.7\%). Mortality rate was $9.6 \%$ for ruptured and $0.2 \%$ for unruptured cerebral aneurysms.

The Spearman's rank correlation coefficient for the relationship between case volume and outcome at discharge was $0.034(\mathrm{p}=0.483)$ and the relationship between WFNS grade on admission and outcome at discharge was 0.60 ( $p<0.001)$ for ruptured cerebral aneurysm clipping at each center. Therefore, outcome at discharge was influenced more strongly by WFNS grade on admission than by case volume. The Spearman's rank correlation coefficient for the relationship between case volume and outcome at discharge was $0.029(\mathrm{p}=0.562)$ for unruptured cerebral aneurysms clipping at each 
Table 4 Hospital classification by number of clippings for cerebral aneurysms

\begin{tabular}{lcccr}
\hline & & & \multicolumn{3}{c}{ Case volume } \\
\cline { 3 - 5 } & Total & $\mathrm{n}<30$ & $\mathrm{n}=30-49$ & $\mathrm{n} \geq 50$ \\
\hline No. of hospitals (\%) & 369 & $208(56.4)$ & $96(26.0)$ & $65(17.6)$ \\
No. of clippings & 11974 & 3755 & 3532 & 4687 \\
$\quad$ ruptured aneurysms (\%) & 7578 & $2631(70.1)$ & $2425(68.7)$ & $2522(53.8)$ \\
$\quad$ unruptured aneurysms (\%) & 4396 & $1124(29.9)^{*}$ & $1107(31.3)^{*}$ & $2165(46.2)^{*}$ \\
\hline
\end{tabular}

$* \mathrm{p}<0.001$.

Table 5 Case volume and clinical grade of patients with ruptured aneurysms

\begin{tabular}{|c|c|c|c|c|c|}
\hline Case volume & \multicolumn{5}{|c|}{ Clinical grade } \\
\hline $\mathrm{n}=30-49$ & $768(31.7)$ & $686(28.3)$ & $209(8.6)$ & $423(17.4)$ & 339 (14.0) \\
\hline $\mathrm{n} \geq 50$ & $757(30.0)$ & $688(27.3)$ & $215(8.5)$ & $488(19.3)$ & 374 (14.8) \\
\hline Total & $2285(30.2)$ & $2130(28.1)$ & 719 (9.5) & 1390 (18.3) & 1054 (13.9) \\
\hline
\end{tabular}

Values are no. of patients (\%). There was no difference in case volume and clinical grade $(\mathrm{p}=0.172)$.

center, so outcomes at discharge were not clearly influenced by case volume (Table 3 ).

The case volume was $<30$ cases/year at 208 centers (56.4\%), 30-49 cases/year at 96 centers $(26.0 \%)$, and $\geq 50$ cases/year at 65 centers $(17.6 \%)$ (Table 4$)$. The Japan Neurosurgical Society conducted a study on cerebral aneurysm clippings performed from January to December 2001, and found that more than half of participating centers satisfied the center standards (30-49 cases/year, 5.4\%; $\geq 50$ cases/year, $48.3 \%) .{ }^{14)}$ The participating centers were not completely the same, but the number of centers satisfying the center standards appears to have declined.

Unruptured cerebral aneurysms accounted for $29.9 \%, 31.3 \%$, and $46.2 \%$ of all aneurysms at centers with case volumes of $<30,30-49$, and $\geq 50$ cases/year, respectively. In other words, the ratio of unruptured cerebral aneurysms was greater with higher case volume ( $\mathrm{p}<0.001$, Table 4$)$, suggesting that patients with unruptured cerebral aneurysms are more likely to be referred to centers with higher case volumes.

The WFNS grade of patients with ruptured cerebral aneurysm on admission was: grade I, $30.2 \%$; grade II, $28.1 \%$; grade III, $9.5 \%$; grade IV, $18.3 \%$; and grade $\mathrm{V}, 13.9 \%$. No significant differences were noted in the distributions of WFNS grade on admission between the three case volume groups (Table 5). There was no significant correlation between case volume, WFNS grade on admis- sion, and outcome at discharge for ruptured cerebral aneurysms (Table 6), or between case volume and outcome at discharge (Table 7).

\section{Discussion}

\section{Surgical skill level as assessed based on mortality rate}

The mortality rate for patients with ruptured cerebral aneurysms was $9.6 \%$ in the present study, lower than the $14-31 \%$ reported in Western countries $^{7,9,11-13)}$ and lower than the $8.8-48.5 \%$ in US studies that investigated relationships between case volume and outcome. ${ }^{1,18)}$ The mortality rate for patients with unruptured cerebral aneurysm was $0.2 \%$ in the present study, also lower than the $1.0-2.6 \%$ reported in Western countries. ${ }^{10,17)}$ A metaanalysis of 28 studies from 1966 to 1992 indicated that the mortality rate for patients with unruptured cerebral aneurysm was $1.0 \%$ (95\% confidence interval [CI] $\left.0.4-2 \%),{ }^{10}\right)$ whereas another meta-analysis of 61 studies from 1966 to 1996 reported a mortality rate of $2.6 \%$ (95\% CI $2-3.3 \%) .{ }^{17)}$ The mortality rate for patients with unruptured cerebral aneurysm was markedly lower in the present study compared to the mortality rates of $4.6-8.1 \%$ in US studies investigating relationships between case volume and outcome. ${ }^{18)}$

Surgical skill level and perioperative management are among the various factors contributing to the 
Table 6 Case volume and outcome after clipping for patients with ruptured aneurysms

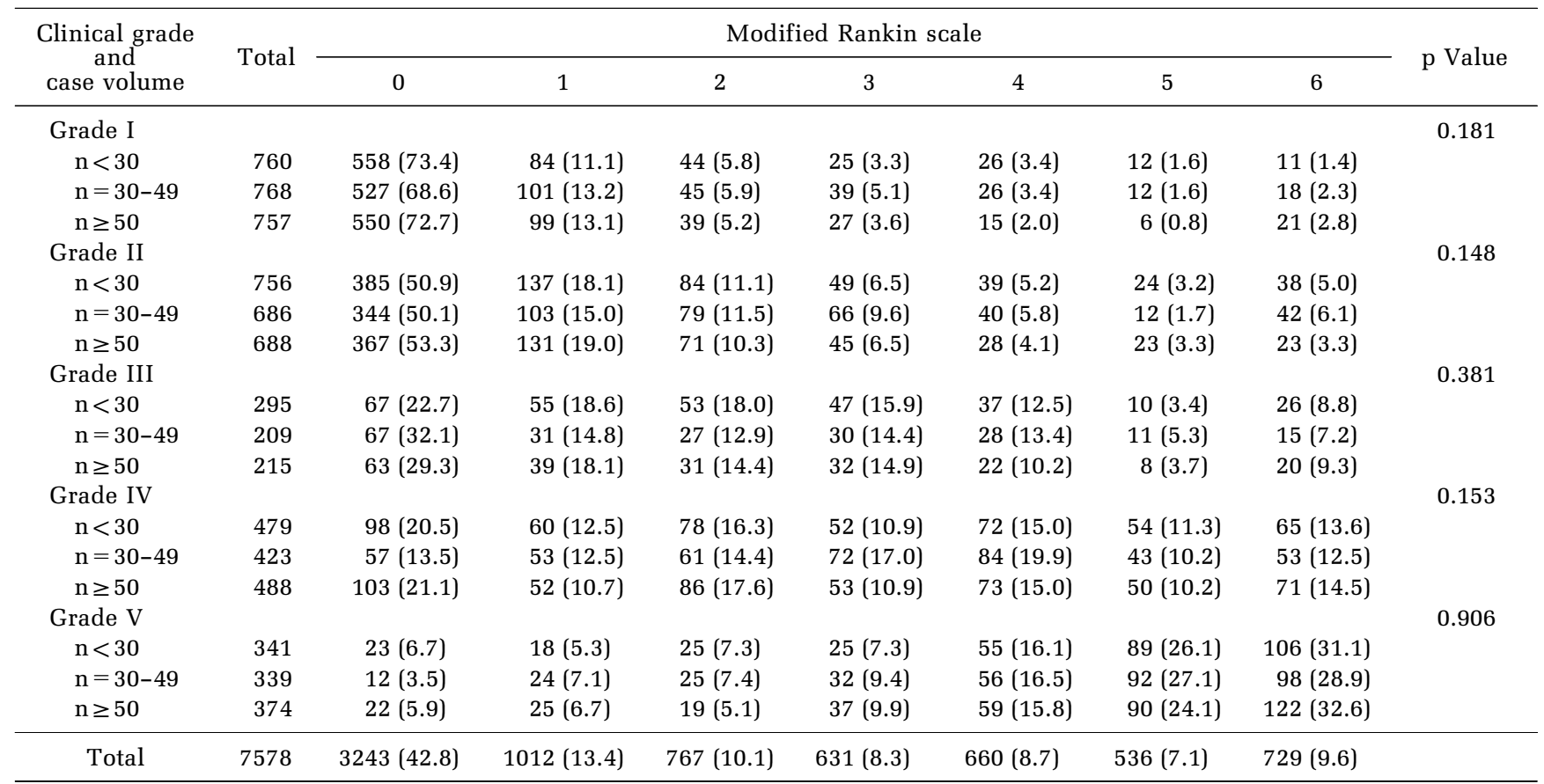

Values are no. of patients (\%). There was no difference in case volume and modified Rankin scale score (not significant by the Kruskal-Wallis test).

Table 7 Case volume and outcome after clipping for patients with unruptured aneurysms

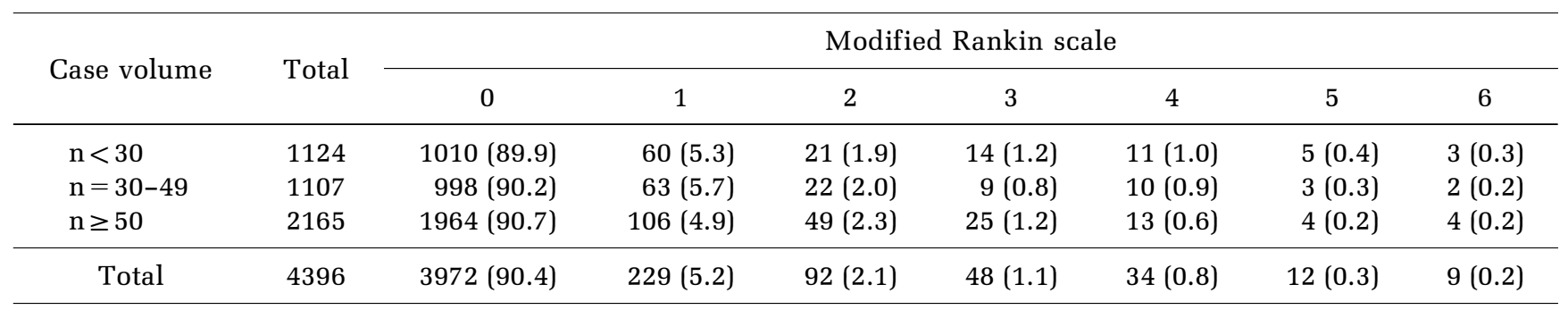

Values are no. of patients (\%). There was no difference in case volume and modified Rankin scale score ( $p=696$ by the Kruskal-Wallis test).

low mortality rates in this study. The effects of perioperative management on mortality rate are limited, particularly with unruptured cerebral aneurysms, whereas the effects of surgical skill level are substantial. This study indicates that the level of surgical skill for cerebral aneurysm clipping is very high.

\section{Relationship between case volume and out- come}

Several studies have investigated the relationships between case volume and outcome in cerebral aneurysm clipping. ${ }^{1,3,5,6,15,18,19)}$ The relationships between case volume and outcome were analyzed in
12,804 surgeries for ruptured cerebral aneurysms performed at 390 centers in California from 1990 to 1999. ${ }^{1)}$ Without distinguishing clipping from endovascular surgery, the mortality rate at centers performing $\geq 19$ surgeries/year was $32.3 \%$, compared to $48.8 \%$ at centers performing $<8$ surgeries/year $(p<0.001)$, whereas the totals of deceased patients and patients transferred to rehabilitation or long-term nursing care facilities were $55.9 \%$ and $76.4 \%$, respectively $(\mathrm{p}<0.001)$. However, a significant difference in age was noted between the two groups (61.9 years vs. 56.0 years, respectively, $\mathrm{p}<0.001$ ), so the relationship between case volume and outcome did not necessarily reflect 
surgical skill level.

The relationships between case volume and outcome were analyzed in cerebral aneurysm clippings performed at 208 centers in New York from 1987 to 1993. ${ }^{18)}$ The mortality rate for 4,034 ruptured cerebral aneurysms was $4.6 \%$ at centers performing $\geq 30$ surgeries/year and $8.1 \%$ at centers performing $<30$ surgeries/year, respectively, representing a significant intergroup difference $(p=0.0087)$.

Analysis of cerebral aneurysm surgeries performed at 257 centers in New York from 1995 to 2000 compared outcomes between 10 high-volume centers, where $\geq 35$ surgeries/year including cerebral aneurysm clipping and endovascular surgery were performed, and all other centers. ${ }^{3)}$ For 3,763 surgeries for ruptured cerebral aneurysms, the mortality rate during hospitalization (odds ratio [OR] $0.95, \mathrm{p}=0.05$ ) and the ratio of patients transferred to rehabilitation and long-term care facilities (OR $0.94, p=0.03$ ) were both significantly lower for high-volume centers. In addition, for 2,000 surgeries for unruptured cerebral aneurysm, the mortality rate during hospitalization (OR 0.94, $\mathrm{p}=0.002$ ) and the ratio of patients transferred to rehabilitation and long-term care facilities (OR 0.89, $\mathrm{p}<0.001$ ) were also significantly lower for high-volume centers.

These US studies assessed outcomes in terms of mortality rate and transfer rate, and involved fairly complicated analyses. Some studies also assessed the effects of not only surgical skill, but also age, sex, and race on outcomes, but none included WFNS grade on admission, which had the largest impact on surgical outcomes for patients with ruptured cerebral aneurysms.

In the present study, outcome at discharge was assessed using a modified Rankin scale, and the grade on admission according to the WFNS scale. Therefore, this study could directly analyze relationships between outcome at discharge and case volume at each center. No significant correlations were seen between outcome at discharge and case volume at each center for both ruptured and unruptured cerebral aneurysms. Furthermore, no significant correlations were found between outcome at discharge and case volume.

\section{Characteristics of cerebral aneurysm clip- ping in Japan}

The above-mentioned US studies support the correlation between outcome and case volume at each center and the idea that greater case volume is associated with higher surgical skill level. However, this finding does not necessarily apply to Japan, given the differences in medical systems, medical levels, and specialist training systems. The present study did not show any significant correlation between outcome and case volume in cerebral aneurysm clipping in Japan. In other words, surgical skill levels appear to be basically similar at centers regardless of case volume.

Surgical skill levels improve with experience, but are also affected by the training of the surgeons. Therefore, a correlation between case volume and outcome should be apparent only if high volume centers have more highly skilled surgeons. The results of the present study show that highly skilled surgeons were performing surgeries at centers with low case volumes in Japan.

Specialist training centers certified by the Japan Neurosurgical Society have strived to establish high standards for cerebral aneurysm clipping. Therefore, many surgeons in Japan are highly skilled at performing cerebral aneurysm clipping. In other words, highly skilled surgeons are available in all 348 medical zones as defined by the Ministry of Health, Labor and Welfare of Japan. This is unique to Japan and is not seen in any other country, including the US. This presumably is the main factor causing the absence of correlation between case volume and outcome at centers with different case volumes.

\section{Validity of the center standards in Japan}

The present study clearly shows that greater case volume is not associated with higher surgical skills in Japan. Therefore, the application of center standards based on case volume is groundless.

The center standards have more serious flaws. The Ministry of Health, Labor and Welfare of Japan has a policy to provide medical care except for advanced care within each medical zone. Patients with ruptured cerebral aneurysm are thus rarely transported to another medical zone for treatment. In fact, such patients can now be treated within each zone. However, the center standards encourage the transport of patients with ruptured cerebral aneurysms to other medical zones. However, such transportation may consume for long periods, which may allow the patient condition to change rapidly and substantially, as well as compromise medical facilities that are functioning correctly within each zone.

The 2006 revision of the medical compensation system will abolish the center standards, but the Ministry of Health, Labor and Welfare of Japan does not appear to have given up on the idea entirely. The Japan Neurosurgical Society needs to gather more data to ensure that enacted policies accurately reflect the actual clinical facilities. 


\section{Acknowledgment}

We wish to express our gratitude to the physicians at specialist training centers that have been certified as Class A by the Japan Neurosurgical Society who participated in the present study.

\section{References}

1) Bardach NS, Zhao S, Gress DR, Lawton MT, Johnston SC: Association between subarachnoid hemorrhage outcomes and number of cases treated at California hospitals. Stroke 33: 1851-1856, 2002

2) Begg CB, Cramer LD, Hoskins WJ, Brennan MF: Impact of hospital volume on operative mortality for major cancer surgery. JAMA 280: 1747-1751, 1998

3) Berman MF, Solomon RA, Mayer SA, Johnston SC, Yung PP: Impact of hospital-related factors on outcome after treatment of cerebral aneurysms. Stroke 34: 2200-2207, 2003

4) Birkmeyer JD, Siewers AE, Finlayson EV, Stukel TA, Lucas FL, Batista I, Welch HG, Wennberg DE: Hospital volume and surgical mortality in the United States. N Engl J Med 346: 1128-1137, 2002

5) Cowan JA Jr, Dimick JB, Thompson BG, Stanley JC, Upchurch GR: Surgeon volume as an indicator of outcomes after carotid endarterectomy: an effect independent of specialty practice and hospital volume. J Am Coll Surg 195: 814-821, 2002

6) Cowan JA Jr, Dimick JB, Wainess RM, Upchurch GR, Thompson BG: Outcome after cerebral aneurysm clip occlusion in the United States: the need for evidence-based hospital referral. J Neurosurg 99: 947-952, 2003

7) de Gans K, Nieuwkamp DJ, Rinkel GJ, Algra A: Timing of aneurysm surgery in subarachnoid hemorrhage: a systematic review of the literature. Neurosurgery 50: 336-342, 2002

8) Drake CG: Report of World Federation of Neurological Surgeons Committee on a Universal Subarachnoid Hemorrhage Grading Scale. J Neurosurg 68: 985-986, 1988

9) Kassell NF, Torner JC, Jane JA, Haley EC Jr, Adams HP: The International Cooperative Study on the Timing of Aneurysm Surgery. Part 2: Surgical results. J Neurosurg 73: 37-47, 1990

10) King JT Jr, Berlin JA, Flamm ES: Morbidity and mortality from elective surgery for asymptomatic, unruptured, intracranial aneurysms: a meta-analysis. J Neurosurg 81: 837-842, 1994

11) Koivisto $T$, Vanninen $R$, Hurskainen $H$, Saari $T$, Hernesniemi J, Vapalahti M: Outcomes of early endovascular versus surgical treatment of ruptured cerebral aneurysms. A prospective randomized study. Stroke 31: 2369-2377, 2000

12) Laidlaw JD, Siu KH: Ultra-early surgery for aneurysmal subarachnoid hemorrhage: outcomes for a consecutive series of 391 patients not selected by grade or age. J Neurosurg 97: 250-258, 2002
13) Molyneux A, Kerr R, Stratton I, Sandercock P, Clarke M, Shrimpton J, Holman R; International Subarachnoid Aneurysm Trial (ISAT) Collaborative Group: International Subarachnoid Aneurysm Trial (ISAT) of neurosurgical clipping versus endovascular coiling in 2143 patients with ruptured intracranial aneurysms: a randomised trial. Lancet 360 (9342): $1267-1274,2002$

14) Nakagawa T, Watanabe K, Kobayashi S: [Results of urgent survey (April 11, 2002) by the Japan Neurosurgical Society, no. 5 in series of articles: controversy and reform proposals concerning insured medical care in neurosurgery]. No Shinkei Geka 30: 901-904, 2002 (Jpn)

15) Naso WB, Rhea AH, Poole A: Management and outcomes in a low-volume cerebral aneurysm practice. Neurosurgery 48: 91-100, 2001

16) Nathens AB, Jurkovich GJ, Maier RV, Grossman DC, MacKenzie EJ, Moore M, Rivara FP: Relationship between trauma center volume and outcomes. JAMA 285: 1164-1171, 2001

17) Raaymakers TW, Rinkel GJE, Limburg M, Algra A: Mortality and morbidity of surgery for unruptured intracranial aneurysms: a meta-analysis. Stroke 29: 1531-1538, 1998

18) Solomon RA, Mayer SA, Tarmey JJ: Relationship between the volume of craniotomies for cerebral aneurysm performed at New York state hospitals and in-hospital mortality. Stroke 27: 13-17, 1996

19) Taylor CL, Yuan Z, Selman WR, Ratcheson RA, Rimm AA: Mortality rates, hospital length of stay, and the cost of treating subarachnoid hemorrhage in older patients: institutional and geographical differences. J Neurosurg 86: 583-588, 1997

20) Tu JV, Austin PC, Chan BT: Relationship between annual volume of patients treated by admitting physician and mortality after acute myocardial infarction. JAMA 285: 3116-3122, 2001

21) van Swieten JC, Koudstaal PJ, Visser MCI, Schouten $\mathrm{HJ}$, van Gijn J: Interobserver agreement for the assessment of handicap in stroke patients. Stroke 19: 604-607, 1988

Address reprint requests to: Naoyuki Hattori, M.D., Department of Neurosurgery, Nihon University School of Medicine, 30-1 Oyaguchi-kamimachi, Itabashi-ku, Tokyo 173-8610, Japan.

e-mail: nh1026@bf6.so-net.ne.jp

\section{Commentary}

As no similar study is available in my country, I read with great interest this article and I admire the initiative of the Japan Neurosurgical Society. Not only is the medical system in Japan different from that of other countries, for instance European ones, the num- 
ber of patients requiring clipping procedures for either ruptured or unruptured cerebral aneurysms is much higher than in Europe, except perhaps for Finland. In addition to this fact, endovascular treatment in Japan has not replaced the clipping procedure in the same fashion as it did, for instance, in Europe. Moreover, Japan possesses a high number of centers specialized for clipping procedures which exceeds by far the capacity available in many other countries. This, however, is also the reason why the case volume of many hospitals is rather low, suggesting a lower level of experience in these centers. It is evident why the Japan Neurosurgical Society has conducted such a nationwide survey based on the tremendous work of neurosurgeons from 369 centers. This important study involving almost 12,000 patients furnishes evidence of high standards for cerebral aneurysm clipping even in low-volume centers of Japan. Such a reassuring result may not have been expected at first glance, and, indeed, is rather unique to Japan. Another merit of the present study is that it demonstrates the efficiency of the medical and neurosurgical training system in Japan in terms of mortality rates and outcome after clipping procedures of cerebral aneurysms. Hopefully, this study will serve as model to other neurosurgical societies for a similar survey.

Helmut BertalanfFy, M.D. Department of Neurosurgery Philipps University Hospital Marburg, Deutschland

This is an interesting and extremely important paper describing that case volume does NOT correlate with outcome after cerebral aneurysm clipping based on a nationwide study in Japan.

There are, I think, three important issues included in this paper. First, this study covers almost all accredited neurosurgeon training facilities by the Japan Neurosurgical Society with high responding rate of $96.6 \%$ to the survey. This indicates that majority of the Japanese responsible and leading neurosurgeons have quite a high interest in this issue. Secondly, 'low volume' hospitals comprise of more than half (56.4\%) in the present study and also many patients (one third) underwent surgery in the 'low volume' hospitals. Thirdly, even with the fact I mentioned as a second issue, the surgical mortality is quite low: 9.6\% for patients with ruptured and 0.2\% for unruptured aneurysms, compared with various studies in other countries including Western countries, where the medical training system is different from that of Japan.

According to these facts, as the authors described, highly skilled surgeons are available in all medical zones even in rural districts. Of course we should not be satisfied with the low mortality rate, because we still have room for further lowering the mortality rate as well as morbidity rate. This paper has, however, a quite important meaning in order to let the personnel of the Japanese government, Ministry of Health, Labor and Welfare of Japan and also the media know the fact that 'hospital volume' or just the 'number of surgeries' itself is not a criterion to judge 'a high quality hospital.'

\section{Kazuhiro Hongo, M.D. Department of Neurosurgery Shinshu University School of Medicine Matsumoto, Japan}

This report by Hattori and colleagues demonstrates that good patient outcomes can be achieved not only by high-volume ( $\geq 50$ cases/year), but by median(30-49 cases/year) and low-volume ( $<30$ cases/year) aneurysm practices. The study is a national survey conducted by the Japan Neurosurgical Society, involving 382 core centers accredited as Class A specialist training facilities. The total surgical mortality for patients with ruptured or unruptured aneurysms were $9.6 \%$ and $0.2 \%$ respectively, reflecting the high level of surgical skill in the centers. The distribution of WFNS grade on admission, which usually impacts on the outcome of patients, were well matched in each case volume, and the modified Rankin scale at discharge in each case volume was not significantly different. Therefore, the result that there was no significant correlation between case volume and outcome for either ruptured or unruptured aneurysms sounds reasonable.

The distribution and size of aneurysms in each case volume that possess negative shadow of patient's outcome, however, were not provided in the report. In my practice, better results of aneurysm surgery (open or endovascular) would be expected for centers with high volume and extensive experience, as well as a committed multidisciplinary team to furnish all available therapeutic options for patients with complex aneurysms, such as large and giant aneurysms, fusiform and dissecting aneurysms, and aneurysms in the posterior circulation.

Liang-Fu ZHOU, M.D. Department of Neurosurgery HuaShan Hospital, S.M.C., F.D.U. Shanghai, P.R.C. 